\title{
Composição Física da Carcaça, Qualidade da Carne e Conteúdo de Colesterol no Músculo Longissimus dorsi de Novilhos 5/8 Nelore - 3/8 Charolês Terminados em Confinamento e Abatidos em Diferentes Estádios de Maturidade ${ }^{1}$
}

\section{Miguelangelo Ziegler Arboitte ${ }^{2}$, João Restle ${ }^{3}$, Dari Celestino Alves Filho ${ }^{4}$, Ivan Luiz Brondani ${ }^{5}$, Paulo Santana Pacheco ${ }^{6}$, Luiz Fernando Glasenapp de Menezes ${ }^{6}$, Juliano Perottoni ${ }^{7}$}

\begin{abstract}
RESUMO - O experimento foi conduzido com o objetivo de avaliar a composição física da carcaça, a qualidade da carne e o conteúdo de colesterol no músculo Longissimus dorsi de novilhos 5/8 Nelore - 3/8 Charolês terminados em confinamento até atingirem o peso de abate (P) de 425, 467 e $510 \mathrm{~kg}$. Os novilhos apresentaram, ao início do confinamento, idade média de 660 dias, peso de 361 kg e estado corporal de 2,9 pontos. A dieta alimentar, com relação volumoso:concentrado de 60:40, continha 10,25\% de proteína bruta, 72,18\% de nutrientes digestíveis totais e 3,18 Mcal de energia digestível/kg MS. A quantidade de músculo ( $\hat{\mathrm{Y}}=15,548+0,316 \mathrm{P}$ ), gordura ( $\hat{Y}=-75,971+0,290 P)$ e de gordura interna $(\hat{Y}=-61,955+0,178 P)$ da carcaça aumentaram linearmente com o incremento do P. Porém, o percentual de músculo decresceu ( $\hat{Y}=90,294-0,059 P$ ), o de gordura ( $\hat{Y}=-5,320+0,060$ P) aumentou e o de osso permaneceu constante $(14,93 \%)$ do menor para o maior P. Não houve influência do peso de abate na relação músculo:osso $(4,28)$ e músculo+gordura:osso $(5,80)$. A cor (4,28 pontos) e textura (3,28 pontos) da carne não foram alteradas, porém o marmoreio cresceu linearmente $(\ddot{Y}=-8,403+0,035 \mathrm{P})$ com o aumento no P. O peso de abate não influenciou a quebra no processo de descongelamento (11,13\%) e de cocção da carne (23,94\%). A maciez da carne foi classificada entre "macia e muito macia” (6,77 pontos), a palatabilidade entre "palatável e muito palatável” (6,77 pontos) e a suculência entre "suculenta e muito suculenta” (6,88 pontos), não sendo influenciadas pelo aumento no P. O músculo Longissimus dorsi apresentou 1,63\% de extrato etéreo e 53,12 mg de colesterol/100 g de músculo, permanecendo constantes com o aumento do P. Houve correlação positiva do percentual de extrato etéreo do músculo Longissimus dorsi com a espessura de gordura (0,42), o marmoreio $(0,46)$ e o teor de colesterol $(0,60)$.
\end{abstract}

Palavras-chave: cor, cruzamento, extrato etéreo, gordura, maciez, marmoreio

\section{Carcass Physical Composition, Meat Quality and Cholesterol Content in the Longissimus dorsi Muscle of 5/8 Nellore - 3/8 Charolais Steers Feedlot Finished and Slaughtered at Different Maturity Stages}

\begin{abstract}
The objective of this experiment was to evaluate the physical carcass composition, meat quality and cholesterol content in the Longissimus dorsi muscle of 5/8 Nellore - 3/8 Charolais steers feedlot finished to reach slaughter weight (SW) of 425, 467 and $510 \mathrm{~kg}$. At the beginning of feedlot, average age, weight and body condition were, respectively, 660 days, $361 \mathrm{~kg}$ and 2.9 points. The diet offered, with roughage:concentrate ratio of 60:40, contained $10.25 \%$ of crude protein, $72.18 \%$ of total digestible nutrients and 3.18 Mcal of digestible energy/kg of DM. The muscle ( $\hat{Y}=15.548+0.316 S W)$, fat $(\hat{Y}=-75.971+0.290$ SW) and internal fat ( $\hat{Y}=-61.955+0.178 \mathrm{SW})$ of the carcass quantity increased linearly as SW increased. However, the muscle percentage declined ( $\hat{Y}=90.294-0.059 P A)$, the fat percentage increased $(\hat{Y}=-5.320+0.060 P A)$ and bone percentage was not alterated (14.93\%) by SW The muscle:bone (4.28) and muscle+fat:bone ratio (5.80) was not influenced by SW. The meat color (4.28 points) and texture (3.28 points) were not influenced, however, marbling increased linearly $(\ddot{Y}=-8.403+0.035 \mathrm{SW})$ as the SW increased. Slaughter weight did not influence meat thawing (11.13\%) and cooking losses (23.94\%). The tenderness was classified between "tender and very tender" (6.77 points), palatability between "flavorful and very flavorful " (6.77 points) and juiciness between "juicy and very juicy" (6.88 points), were not influenced by SW. The Longissimus dorsi muscle showed 1.63\% of ether extract and $53.12 \mathrm{mg}$ of cholesterol/100 g of muscle, remaining constant with SW increase. Positive correlation of ether extract percentage in the Longissimus dorsi muscle with subcutaneous fat thickness (0.42), with marbling score (0.46) and with cholesterol content (0.60) was observed.
\end{abstract}

Key Words: crossbreeding, ether extract, fat, tenderness, marbling, meat color

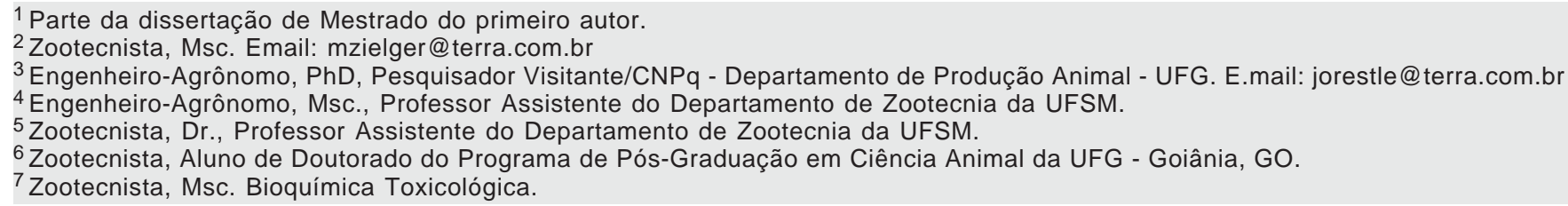




\section{Introdução}

Com a atual realidade econômica do país, o produtor necessita manter-se competitivo em sua atividade, sendo necessário investimento em eficiência produtiva para aumentar a lucratividade. Por muito tempo, a carne bovina comercializada no país provinha de animais com idade média de três a cinco anos, gerando produto de baixa qualidade e de baixa eficiência econômica.

Para aumentar a eficiência produtiva, existem alternativas à disposição do produtor rural, como o uso do confinamento, que traz inúmeros benefícios aumento do ganho de peso em épocas com restrições quantitativas e qualitativas do pasto, melhor aproveitamento da terra, por meio da concentração de animais em pequenas áreas e melhoria na qualidade da carcaça e da carne dos animais (Restle et al., 1998). Além disso, o cruzamento permite ao produtor buscar genótipos mais adequados ao seu sistema de produção que atendam à demanda do mercado, principalmente no quesito qualidade de carcaça e de carne (Restle et al., 1999). Melhorar o nível de alimentação na terminação, associado ao material genético com potencial para ganho de peso, é a combinação que certamente trará retorno econômico ao sistema de produção.

A carne bovina precisa ser mais competitiva em relação à de outras espécies, como aves e suínos, que possuem controle rigoroso de qualidade. Portanto, é necessário investir nos aspectos qualitativos, destacando-se as características sensoriais, visando cativar o consumidor brasileiro e ampliar a competição no mercado externo, que tem sido a grande alavanca para incentivo e crescimento da atividade.

Restle et al. (1996) citam que os frigoríficos, em geral, pagam melhores preços por animais de maior peso, pois obtém com isso maior rendimento por unidade de animal abatido, resultando em músculos de maior tamanho, preferidos tanto pelo mercado interno como pelo externo. Contudo, alguns estudos mostram que, ao elevar o peso de abate dos animais, pode ocorrer queda na maciez da carne (Van Koevering et al., 1995; Restle et al., 1999; Vaz et al., 2002), sendo a maciez correlacionada positivamente com a palatabilidade e suculência da carne (Field et al., 1966; Wheeler et al., 1996).

O grau de acabamento da carcaça é outro aspecto importante na comercialização, pois frigoríficos exigem grau de acabamento adequado para evitar escurecimento dos músculos externos durante o resfriamento, além de influenciar as características sensoriais da carne (Preston \& Willis, 1970; Müller, 1987; Vaz \& Restle, 2000).

O colesterol - importante componente na dieta de seres humanos - auxilia na produção hormonal das glândulas sexuais e adrenal e no transporte e absorção das vitaminas lipossolúveis (Valle, 2003). Contudo, atualmente, tem-se enfatizado o estudo da quantidade de lipídios e colesterol presentes na carne bovina, em razão da preocupação mundial quanto ao consumo excessivo de alimentos com alta densidade calórica e seus efeitos nocivos à saúde humana. Resultados de pesquisas demonstraram que a concentração de colesterol do músculo Longissimus dorsi pode não apresentar aumento significativo com o avanço do período de terminação, em bovinos de corte (Wheeller et al., 1987; Costa et al., 2002). Em outros estudos, porém, foi observado acréscimo linear com o avanço do período de terminação (Terrel et al., 1969; Van Koevering et al., 1995; Xie et al., 1996).

O objetivo deste trabalho foi avaliar o efeito da terminação em confinamento de novilhos 5/8 Nelore - 3/8 Charolês abatidos com diferentes pesos na composição física da carcaça, na qualidade da carne e no conteúdo de colesterol do músculo Longissimus dorsi.

\section{Material e Métodos}

O experimento foi conduzido no Setor de Bovinocultura de Corte do Departamento de Zootecnia da Universidade Federal de Santa Maria, situada na Depressão Central do Rio Grande do Sul, com coordenadas $29^{\circ} 42^{\prime}$ de latitude Sul e $54^{\circ} 42^{\prime}$ ' de longitude Oeste e 96 metros de altitude.

Foram avaliadas a composição física da carcaça e as características qualitativas da carne de 18 novilhos contemporâneos do grupo genético 5/8 Nelore - 3/8 Charolês, castrados e provenientes do mesmo rebanho. Os animais foram terminados em confinamento e abatidos com pesos de 427, 467 e $510 \mathrm{~kg}$, inicialmente pretendidos de 420, 460 e $510 \mathrm{~kg}$.

Durante o período de confinamento, os animais foram alimentados ad libitum com dieta contendo 10,25\% de proteína bruta e 3,18 Mcal de energia digestível/kg de matéria seca (MS), duas vezes ao dia (8 e 17h). A dieta foi calculada segundo o NRC (1996), objetivando ganho de peso médio diário de $1,600 \mathrm{~kg} / \mathrm{animal} / \mathrm{dia}$, estimando-se consumo de $2,5 \mathrm{~kg}$ de matéria seca (MS)/100 kg de peso vivo (PV), 
sendo a relação volumoso:concentrado de 60:40, com base na MS (Tabela 1).

Quando os animais atingiram peso próximo ao pretendido, foram submetidos a jejum de sólidos de 14 horas, pesados (peso de fazenda) e transportados para um frigorífico comercial distante $25 \mathrm{~km}$ da Fazenda Experimental, onde foram abatidos imediatamente após a chegada.

Por ocasião do abate, as carcaças foram resfriadas em câmara fria por 24 horas, à temperatura de 0 a $1^{\circ} \mathrm{C}$. Após esse período de resfriamento, as meiacarcaças foram novamente pesadas para obtenção do peso de carcaça fria.

Para determinação do percentual de músculo, gordura e osso (composição física da carcaça), na meia-carcaça direita foi realizada uma secção entre a 10-11-12 ${ }^{\mathrm{a}}$ costelas, efetuando-se a separação física destes tecidos, conforme metodologia proposta por Hankins \& Howe (1946) e adaptada por Müller et al. (1973).

A espessura de gordura subcutânea foi determinada pela média aritmética de três mensurações ao redor do músculo Longissimus dorsi, na altura da $12^{\mathrm{a}}$ costela. Também neste local, sobre a face exposta do músculo Longissimus dorsi exposto ao ar por 30 minutos, foram feitas as avaliações subjetivas de cor, textura e marmoreio da carne, atribuindo valores conforme escala proposta por Müller (1987).

As amostras de músculo Longissimus dorsi extraídas das peças seccionadas foram identificadas, embaladas em lâmina de filme de polietileno e papel pardo e imediatamente congeladas a $-18^{\circ} \mathrm{C}$.

Das amostras ainda congeladas, foram retiradas duas fatias de 2,5 cm de espessura. Uma das fatias (fatia A) foi pesada congelada e descongelada, para determinação da quebra durante o processo de descongelamento da carne, e cozida até atingir temperatura interna de $70^{\circ} \mathrm{C}$ por 15 minutos, para avaliação da quebra no processo de cocção da carne. Nesta mesma fatia, após o cozimento, foram retiradas três amostras no sentido longitudinal às fibras musculares, realizando-se duas leituras em cada uma, pelo aparelho Warner Bratzler Shear, para determinação da força de cisalhamento da carne. Na outra fatia (fatia B), foi realizada a avaliação sensorial da carne (maciez, palatabilidade e suculência) por um painel de cinco degustadores treinados, que atribuíram valores de 1 (carne extremamente dura, impalatável e sem suculência) a 5 (carne extremamente macia, palatável e suculenta), seguindo a metodologia de Müller (1987).
Para determinação do conteúdo de extrato etéreo e colesterol, foi empregada a metodologia de Folch et al. (1957), utilizando uma fatia de $5 \mathrm{~cm}$ do músculo Longissimus dorsi.

O delineamento experimental foi o inteiramente casualizado com três tratamentos e seis repetições. O peso inicial foi considerado como covariável, para melhor ajuste dos dados. Os dados foram submetidos à análise de regressão, por intermédio do programa estatístico SAS (1997).

O modelo estatístico utilizado foi:

$$
\mathrm{Y}_{\mathrm{ij}}=\mathrm{B} 0+\mathrm{B} \mathrm{PA}_{\mathrm{ij}}+\mathrm{B} \mathrm{PA}^{2}{ }_{\mathrm{ij}}+\mathrm{E}_{\mathrm{ij}}
$$

em que $\mathrm{Y}_{\mathrm{ij}}=$ variáveis dependentes; $\mathrm{B} 0, \mathrm{~B} 1, \mathrm{~B} 2$ = parâmetros da equação a serem estimados; $\mathrm{PA}_{\mathrm{ij}}=$ peso de abate na repetição ${ }_{j}$ do tratamento ${ }_{i} ; \mathrm{E}_{\mathrm{ij}}=$ erro experimental da observação ${ }_{\mathrm{ij}}$, NID $\left(0, \sigma^{2}\right)$.

\section{Resultados e Discussão}

Na Tabela 2, constam as médias para peso e porcentagem dos tecidos da carcaça, relação músculo:osso, porção comestível:osso e gordura interna.

A espessura de gordura subcutânea aumentou linearmente com o aumento do peso de abate dos animais. O maior incremento foi verificado quando o peso de abate dos animais passou de 425 para $467 \mathrm{~kg}$ (2,76 mm), enquanto dos 467 aos $510 \mathrm{~kg}$ o aumento foi menos acentuado (1 mm).

A quantidade de osso elevou-se $(\mathrm{P}=0,0938)$ com o aumento do peso de abate. Quando a quantidade de

Tabela 1 - Composição da dieta, base matéria seca Table 1 - Diet composition, dry matter basis

\begin{tabular}{lc}
\hline $\begin{array}{l}\text { Ingredientes } \\
\text { Ingredients }\end{array}$ & $\%$ \\
\hline $\begin{array}{l}\text { Silagem de milho } \\
\text { Corn silage }\end{array}$ & 60,00 \\
$\begin{array}{l}\text { Farelo de trigo } \\
\text { Wheat bran }\end{array}$ & 28,24 \\
$\begin{array}{l}\text { Sorgo grão } \\
\text { Sorghum grain }\end{array}$ & 10,07 \\
$\begin{array}{l}\text { Uréia } \\
\text { Urea }\end{array}$ & 0,17 \\
$\begin{array}{l}\text { Calcário calcítico } \\
\text { Limestone } \\
\text { NaCl }\end{array}$ & 1,02 \\
$\begin{array}{l}\text { Rumensin } \\
\text { Rumensin }\end{array}$ & 0,48 \\
\hline
\end{tabular}


osso foi expressa por $100 \mathrm{~kg}$ de carcaça fria, a relação deixou de existir, oscilando entre 14,43 e $15,22 \%$. Estes resultados indicam haver maior nível de crescimento deste tecido na fase inicial da vida do animal. Alguns autores verificaram que a porcentagem de osso diminuiu com o avanço da maturidade dos bovinos (Galvão et al., 1991; Restle et al., 1997), porém nestes estudos não foram relatados os pesos absolutos, indicando que esta variação foi reflexo do aumento percentual dos demais tecidos da carcaça (músculo e/ou gordura).

O percentual de tecido adiposo da carcaça sofreu maior incremento dos 425 aos $467 \mathrm{~kg}$ (19,11 para 23,95\%), estabilizando-se dos 467 aos $510 \mathrm{~kg}$ (23,95 para 23,92\%); a equação que melhor se ajustou ao comportamento dos dados foi a linear. A porcentagem de gordura na carcaça acompanhou o comportamento da variação na espessura de gordura subcu- tânea, sendo a correlação entre estas duas variáveis elevada e altamente significativa ( $\mathrm{r}=0,78 ; \mathrm{P}=0,0001)$.

$\mathrm{O}$ incremento linear do percentual de gordura na carcaça com o aumento do peso de abate dos animais, concorda com os resultados relatados por Restle et al. (1997) e Costa et al. (2002). De acordo com Berg \& Butterfield(1976), a maior deposição de gordura ocorre no estádio de desenvolvimento mais avançado do animal, ratificando a hipótese de Boggs \& Merkel (1979) de que, durante a fase de crescimento do animal, a gordura é o tecido que apresenta desenvolvimento mais tardio, mas é depositado em todas as idades, desde que o consumo de energia exceda ao requerimento do animal para mantença e crescimento.

Para a gordura interna total, o aumento foi de $28 \%$ dos 425 aos $467 \mathrm{~kg}$ e ainda maior dos 467 aos $510 \mathrm{~kg}$ (59\%), indicando que a deposição de gordura ocorreu continuamente na cavidade interna dos animais, com o

Tabela 2 - Médias para espessura de gordura subcutânea (EGS), peso e percentagem de osso, músculo e gordura, relação de músculo/osso (RM:O) e de porção comestível/osso (RPC:O), total de gordura interna (GIT) em $\mathrm{kg}$ e por $100 \mathrm{~kg}$ de peso corporal vazio (PCV), de acordo com o peso de abate

Table 2 - Means for subcutaneous fat thickness (FT), bone, muscle and fat weight and percentage, internal fat in $\mathrm{kg}(I F)$ and IF per $100 \mathrm{~kg}$ of empty body weight (EB), muscle:bone ratio (M:B) and muscle+fat:bone ratio $(M+F: B)$, according to the slaughter weight

\begin{tabular}{|c|c|c|c|c|}
\hline \multirow[t]{2}{*}{$\begin{array}{l}\text { Variáveis } \\
\text { Variable }\end{array}$} & \multicolumn{3}{|c|}{$\begin{array}{l}\text { Peso de abate } \\
\text { Slaughter weight }\end{array}$} & \multirow[t]{2}{*}{$\begin{array}{c}\text { Equação de regressão } \\
\text { Regression equation }\end{array}$} \\
\hline & P425 & P467 & P510 & \\
\hline $\begin{array}{l}\text { EGS,mm } \\
F T, m m\end{array}$ & $3,57 \pm 1,09$ & $6,33 \pm 1,54$ & $7,33 \pm 0,87$ & $Y=-15,914+0,047 P^{b}$ \\
\hline $\begin{array}{l}\text { Osso, \% } \\
\text { Bone, \% }\end{array}$ & $15,22 \pm 0,99$ & $14,43 \pm 3,98$ & $15,15 \pm 5,14$ & $Y=14,93 \pm 1,72$ \\
\hline $\begin{array}{l}\text { Osso, kg } \\
\text { Bone, \% }\end{array}$ & $34,68 \pm 6,70$ & $37,36 \pm 4,13$ & $43,58 \pm 13,22$ & $Y=-12,630+0,111 P^{c}$ \\
\hline $\begin{array}{l}\text { Músculo, \% } \\
\text { Muscle, \% }\end{array}$ & $66,11 \pm 3,90$ & $62,39 \pm 4,18$ & $61,42 \pm 3,02$ & $Y=90,294-0,059 P^{d}$ \\
\hline $\begin{array}{l}\text { Músculo, kg } \\
\text { Muscle, } \mathrm{kg}\end{array}$ & $148,67 \pm 14,76$ & $162,13 \pm 24,22$ & $174,09 \pm 22,06$ & $\mathrm{Y}=15,548+0,316 \mathrm{P}^{\mathrm{e}}$ \\
\hline $\begin{array}{l}\text { Gordura, \% } \\
\text { Fat, \% }\end{array}$ & $19,11 \pm 2,96$ & $23,95 \pm 3,98$ & $23,92 \pm 5,14$ & $Y=-5,320+0,060 P^{f}$ \\
\hline $\begin{array}{l}\text { Gordura , kg } \\
\text { Fat, kg }\end{array}$ & $43,27 \pm 11,45$ & $62,03 \pm 8,14$ & $67,79 \pm 13,60$ & $Y=-75,971+0,290 \mathrm{P}^{\mathrm{g}}$ \\
\hline $\begin{array}{l}\text { GIT, kg } \\
I F, k g\end{array}$ & $13,72 \pm 3,86$ & $17,60 \pm 2,13$ & $27,93 \pm 4,72$ & $\mathrm{Y}=-61,955+0,178 \mathrm{P}^{\mathrm{h}}$ \\
\hline $\begin{array}{l}\text { GIT/PCV, \% } \\
I F / E B, \%\end{array}$ & $3,69 \pm 0,80$ & $4,27 \pm 0,67$ & $6,05 \pm 0,80$ & $Y=-8,863+0,029 P^{i}$ \\
\hline $\begin{array}{l}\mathrm{RM}: \mathrm{O} \\
M: B\end{array}$ & $4,34 \pm 0,52$ & $4,32 \pm 0,40$ & $4,02 \pm 0,63$ & $Y=4,23 \pm 0,5^{1}$ \\
\hline $\begin{array}{l}\mathrm{RPC}: \mathrm{O} \\
M+F: B\end{array}$ & $5,60 \pm 0,45$ & $5,99 \pm 0,34$ & $5,63 \pm 1,05$ & $Y=5,71 \pm 0,66$ \\
\hline
\end{tabular}

${ }^{b} R^{2}=0,6326, P=0,0001 ;{ }^{c} R^{2}=0,1655, P=0,0938 ;{ }^{d} R^{2}=0,2336, P=0,0422 ;$ e $R^{2}=0,2306, P=0,0437 ;{ }^{f} R^{2}=0,1988, P=0,0636$; $\mathrm{g}^{2}=0,4411, \mathrm{P}=0,0026 ;{ }^{\mathrm{h}} \mathrm{R}^{2}=0,7076, \mathrm{P}=0,0001 ;{ }^{i} \mathrm{R}^{2}=0,6214, \mathrm{P}=0,0001$. 
avanço do período de terminação. Conforme estimado pela equação de regressão, houve aumento linear de $0,178 \mathrm{~kg}$ para cada $\mathrm{kg}$ a mais no peso de abate. Observa-se que, embora a porcentagem de gordura da carcaça tenha se mantido praticamente inalterada, quando o peso de abate passou de 467 para $510 \mathrm{~kg}$, houve acréscimo de $1 \mathrm{~mm}$ na espessura de gordura e de 59\% na gordura total interna. Isto indica que a intensidade com que o tecido adiposo é depositado é influenciada pelo local de deposição.

Quando a quantidade de gordura interna foi ajustada em relação a $100 \mathrm{~kg}$ de peso de corpo vazio, a variação seguiu o mesmo comportamento, passando de 3,69 para $6,05 \%$, quando o peso de abate dos animais se elevou de 425 para $510 \mathrm{~kg}$. A equação de regressão estimou aumento de $0,029 \%$ para cada $\mathrm{kg}$ a mais no peso de abate. Williams et al. (1989), avaliando o efeito do período de alimentação nas características de carcaça de novilhos de corte terminados em confinamento, observaram que a porcentagem de gordura removida da carcaça durante o toalete aumentou dos 84 aos 112 dias (5,89 vs 7,03\%), estabilizando-se dos 112 aos 140 dias de confinamento (7,03 vs 7,50\%), corroborando os resultados obtidos por Xie et al. (1996), quando estudaram o tempo de alimentação de novilhos por 90 (2,50\%) ou 170 dias (3,27\%).

Para a quantidade de músculo na carcaça, a equação de regressão estimou aumento de $0,316 \mathrm{~kg}$ para cada kg a mais no peso de abate dos novilhos. Porém, quando se avaliou o percentual deste tecido em relação ao peso de carcaça fria, houve queda de $0,059 \%$ para cada kg a mais no peso de abate, considerando os pesos extremos a queda foi de $7,1 \% / 100 \mathrm{~kg}$ de carcaça fria. Entre os tecidos que compõem a carcaça, o músculo é o que apresenta maior importância comercial, por ser o mais desejado pelo consumidor, além de representar relevante importância nutricional, em razão de sua adequada proporção de aminoácidos essenciais, lipídios, vitaminas e sais minerais para a alimentação humana. Berg \& Butterfield (1976) acrescentam que a carcaça deve apresentar quantidade máxima de músculo, mínima de osso e adequada de gordura, que varia em função do mercado consumidor. Comparando a porcentagem de músculo na carcaça, com à obtida em outros trabalhos, que também avaliaram animais abatidos com diferentes pesos, verificou-se que esta foi semelhante à relatada por Galvão et al. (1991), inferior à observada por Restle et al. (1997), em novilhos Charolês, e superior à reportada por Jorge et al. (1999), em novilhos zebuínos.
Em relação aos componentes físicos da carcaça, dos 425 aos $510 \mathrm{~kg}$ de peso vivo houve aumento na quantidade absoluta de ossos (25,7\%) e músculos $(17,1 \%)$ na carcaça, enquanto na quantidade de gordura foi superior (56,7\%), indicando que, na fase de terminação, sob as mesmas condições nutricionais, o tecido adiposo é o que se deposita com maior intensidade na carcaça. Ao avaliarem o aumento dos três tecidos que compõem a carcaça, Costa et al. (2002) verificaram que elevar o peso de abate de 340 para $430 \mathrm{~kg}$ de novilhos Red Angus resultou em incremento de 24,1 e $23,8 \%$, respectivamente, no peso de músculo e osso e de $60,2 \%$ no peso de gordura.

A relação músculo:osso na carcaça apresentou similaridade (média de 4,28). Da mesma forma, a relação músculo+gordura:osso, que representa a porção comestível da carcaça em relação à quantidade de osso, não variou com o avanço do peso de abate dos novilhos (média de 5,80). Este resultado pode ser explicado pelo aumento numérico na quantidade de osso da carcaça, passando de 34,68 para 43,58 kg do menor para o maior peso de abate, que acompanhou o aumento significativo da quantidade de músculo e gordura da carcaça.

Trabalhando com animais Nelore e F1 Nelore $\mathrm{x}$ Bos taurus abatidos com 90, 100 e $110 \%$ do peso adulto, Galvão et al. (1991) relataram relação músculo:osso similar à do presente experimento. Quando avaliaram a influência do peso de abate nas características de carcaça em novilhos Red Angus, Costa et al. (2002) verificaram similaridade na relação músculo:osso $(4,40)$ e efeito quadrático na relação porção comestível:osso, apresentando valor máximo de 6,47 em animais abatidos aos $395 \mathrm{~kg}$. Trabalhando com novilhos Ibagé abatidos aos 377, 413, 454, 498 e $533 \mathrm{~kg}$, Del Duca et al. (1999) reportam relação músculo+gordura:osso de 3,4; 3,7; 3,8; 4,0 e 4,0, respectivamente.

Na Tabela 3, encontram-se os valores médios referentes às avaliações subjetivas da coloração, textura e marmoreio da carne.

A coloração da carne variou de 3,83 (vermelho levemente escuro a vermelho) a 4,66 pontos (vermelho a vermelho vivo), não apresentando diferença significativa entre os diferentes pesos de abate, com média de 4,28 pontos. Costa et al. (2002) não observaram influência do peso de abate na coloração da carne (classificada como de coloração "vermelha”) de novilhos Red Angus superprecoces abatidos com 340 a $430 \mathrm{~kg}$. Moody et al. (1970) verificaram que a

\section{R. Bras. Zootec., v.33, n.4, p.959-968, 2004}


coloração da carne variou de "vermelho escuro" nos animais alimentados por 28 dias a "vermelho" nos animais alimentados por 84 e 112 dias. Müller (1987) comenta que a cor da carne é uma característica importante sob o ponto de vista comercial, uma vez que o consumidor rejeita a carne com coloração mais escura.

A cor da carne escureceu quando o peso de abate passou de 467 para $510 \mathrm{~kg}$ (4,66 para 3,83 pontos). Isto é explicado pelo aumento da quantidade de mioglobina na carne (Boogs \& Merkel, 1979; Restle et al., 1996) e pela maior concentração de glicogênio muscular (Lawrie, 1981) com o avanço da idade e/ou peso do animal. Restle et al. (1996) verificaram que a coloração da carne passou da classificação "vermelha" para "vermelha escura", quando o peso de abate dos novilhos Charolês aumentou de 421 para 495 kg. Porém, Vaz et al. (2001), ao estudarem vacas de descarte Charolês agrupadas nas classes de idades de quatro, cinco ou seis, sete ou oito e mais de oito anos de idade, observaram que a coloração da carne não diferiu entre os tratamentos avaliados.

Assim como a cor, a textura da carne não foi influenciada pelo peso de abate, apresentando, em média, 3,28 pontos, classificada como "levemente grosseira”. De acordo com Müller (1987), a textura da carne representa a granulação da superfície da carne, constituída por um conjunto de fibras musculares agrupadas em fascículos envolvidos por uma tênue camada de tecido conectivo, o perimício. Semelhança na textura da carne foi relatada por Costa et al. (2002) (4,08), estudando as características da carne de novilhos Red Angus abatidos com diferentes pesos.

De acordo com a equação de regressão, o marmoreio aumentou linearmente 0,035 pontos para cada kg a mais no peso de abate, passando de 6,17 pontos aos $425 \mathrm{~kg}$ para 9,00 pontos aos $510 \mathrm{~kg}$ (diferença de 45,9\%). O marmoreio da carne dos animais abatidos com $425 \mathrm{~kg}$ foi classificado como “leve”, enquanto nos animais abatidos com 467 e 510 kg foi classificado como "pequeno". A correlação entre o grau de marmoreio da carne e o peso de carcaça fria e a espessura de gordura subcutânea foi positiva $(\mathrm{r}=0,40 ; \mathrm{P}=0,1047$ e $\mathrm{r}=0,24 ; \mathrm{P}=0,3400)$, embora não-significativa. Relação positiva do marmoreio com o peso de carcaça fria também foi verificada por Restle et al. (1996) $(\mathrm{r}=0,50)$ e Restle et al. (2001) $(\mathrm{r}=0,63)$, estudando novilhas $3 / 4$ Charolês $1 / 4$ Nelore, e Costa et al. (2002) $(\mathrm{r}=0,53)$.

O marmoreio é uma característica importante, pois está intimamente relacionado às características sensoriais da carne possíveis de serem percebidas e apreciadas pelo consumidor (Costa et al., 2002). No presente estudo, o marmoreio correlacionou-se positivamente com a palatabilidade da carne $(r=0,28$; $\mathrm{P}=0$,2641), embora não significativo. Em países como Estados Unidos, Austrália, Canadá e Japão, a gordura de marmoreio é o principal fator de classificação das

Tabela 3 - Médias para cor, textura, marmoreio e marmoreio por 100 kg de carcaça fria (Marm CF) da carne, de acordo com o peso de abate

Table 3 - Means for meat color, texture, marbling and marbling per $100 \mathrm{~kg}$ of cold carcass (Marb $\mathrm{CC})$, according to the slaughter weight

\begin{tabular}{lcccc}
\hline $\begin{array}{l}\text { Variáveis } \\
\text { Variable }\end{array}$ & \multicolumn{3}{c}{$\begin{array}{c}\text { Peso de abate } \\
\text { Slaughter weight }\end{array}$} & $\begin{array}{c}\text { Equação de regressão } \\
\text { Regression equation }\end{array}$ \\
\cline { 2 - 4 } & $\mathrm{P} 425$ & $\mathrm{P} 467$ & $\mathrm{P} 510$ & \\
\hline $\begin{array}{l}\text { Cor, pontos } \\
\text { Color, points }\end{array}$ & $4,33 \pm 0,82$ & $4,66 \pm 0,52$ & $3,83 \pm 0,75$ & $\mathrm{Y}=4,28 \pm 0,75$ \\
$\begin{array}{l}\text { Textura, pontos } \\
\text { Texture, points }\end{array}$ & $3,50 \pm 0,55$ & $3,17 \pm 0,75$ & $3,17 \pm 0,75$ & $\mathrm{Y}=3,28 \pm 0,67$ \\
$\begin{array}{l}\text { Marmoreio, pontos } \\
\text { Marbling, points }\end{array}$ & $6,17 \pm 2,04$ & $8,50 \pm 2,26$ & $9,00 \pm 3,58$ & $\mathrm{Y}=-8,403+0,035 \mathrm{~Pa}$ \\
$\begin{array}{l}\text { Marm CF, pontos } \\
\text { Marb CC, points }\end{array}$ & $2,84 \pm 1,28$ & $3,27 \pm 4,17$ & $3,17 \pm 1,15$ & $\mathrm{Y}=3,09 \pm 1,03$ \\
\hline
\end{tabular}

\footnotetext{
$\mathrm{a}^{2}=0,1742, \mathrm{P}=0,0842$.

11 - escura; 2 - vermelho escura; 3 - vermelho levemente escura; 4 - vermelha; 5 - vermelho vivo.

11 - dark; 2 - dark red; 3 - light dark red; 4 - red; 5 - bright red.

21 - muito grosseira; 2 - grosseira; 3 - levemente grosseira; 4 - fina; 5 - muito fina.

21 - very coarse; 2 - coarse; 3 - light coarse; 4 - fine; 5 - very fine.

${ }^{3}$ Marmoreio: 1 a 3 - traços; 4 - leve; 7 - pequeno; 10 - médio; 13 - moderado; 16 a 18 - abundante.

${ }^{3}$ Marbling: 1 to 3 - traces; 4 -light; 7 -small; 10 - mean; 13 - moderate; 16 to 18 - abundant.
} 
carcaças e de remuneração. Ao alimentarem novilhos mestiços britânicos x continentais por 105, 119, 133 e 147 dias, Van Koevering et al. (1995) constataram que o marmoreio passou de "leve", para os animais alimentados por 105 dias, para "pequeno," a partir deste período de alimentação. Os autores comentam ainda que o depósito de gordura intramuscular se dá até determinado período de terminação, quando o animal atinge seu potencial genético para acúmulo de marmoreio, em função de sua genética e tamanho à maturidade.

Estudando o desenvolvimento de vacas alimentadas por 0, 14, 28, 42 ou 56 dias, Schnell et al. (1997) não verificaram $(\mathrm{P}>0,05)$ influência no tempo de alimentação na deposição de marmoreio nas carcaças, sendo estas classificadas como "traços" para as vacas alimentadas por 0 e 14 dias e "leve" nos animais alimentados por 28, 42 e 56 dias, provavelmente, em razão do pequeno número de dias entre os períodos. May et al. (1992) constataram em animais Hereford x Angus que a deposição de marmoreio apresentou comportamento quadrático, à medida que aumentou o tempo de alimentação, sendo o maior índice observado aos 112 dias de alimentação. Comparando novilhos de 2,5 anos com vacas de descarte,
Towsend (1991) verificaram marmoreio similar entre estas categorias, classificando como "leve" e Restle et al. (2001) observaram maior grau de marmoreio em vacas de descarte que em novilhas.

Os valores referentes às características sensoriais da carne, força de cizalhamento (Shear) e quebra durante os processos de descongelamento e cocção da carne são apresentados na Tabela 4.

A quebra durante o descongelamento e a cocção não foi afetada pelo peso de abate.

A maciez da carne determinada pelo aparelho Warner-Bratzeer Shear não foi influenciada pelo peso de abate (média de $3,78 \mathrm{kgf} / \mathrm{cm}^{3}$ ), comportamento semelhante também verificado na maciez avaliada pelo painel de degustadores, sendo classificada entre acima da média (6 pontos) e muito macia (8 pontos). A maior pontuação em termos de maciez foi para a carne dos animais abatidos com $425 \mathrm{~kg}, 7,17$ pontos acima da pontuação 7 , que indica carne macia. Houve tendência numérica da maciez da carne decrescer com o aumento do peso de abate, verificada tanto pelo Shear, passando de 3,61 para 3,95 kgf/ $\mathrm{cm}^{3}$ do menor para o maior peso de abate, como pelo painel (7,17 para 6,50 pontos, citados na mesma ordem). O decréscimo na maciez da carne está

Tabela 4 - Médias para quebra no descongelamento (QDesc) e na cocção (QCoc), maciez pelo WB Shear e pelo painel (painel), palatabilidade (Palat) e suculência (Sucul) da carne, de acordo com o peso de abate

Table 4 - Means for meat thawing (TL) and coocking losses (QL), WB Shear, panel tenderness (Panel), palatability (Palat) and juiciness (Juice), according to the slaughter weight

\begin{tabular}{|c|c|c|c|c|}
\hline \multirow[t]{2}{*}{$\begin{array}{l}\text { Variáveis } \\
\text { Variable }\end{array}$} & \multicolumn{3}{|c|}{$\begin{array}{l}\text { Peso de abate } \\
\text { Slaughter weight }\end{array}$} & \multirow{2}{*}{$\begin{array}{c}\text { Médias } \\
\text { Means }\end{array}$} \\
\hline & P425 & P467 & P 510 & \\
\hline $\begin{array}{l}\text { QDesc, \% } \\
T L, \%\end{array}$ & $11,45 \pm 1,96$ & $9,60 \pm 4,50$ & $12,34 \pm 1,40$ & $Y=11,13 \pm 3,01$ \\
\hline $\begin{array}{l}\text { QCoс, \% } \\
Q L, \%\end{array}$ & $24,07 \pm 6,57$ & $26,59 \pm 6,43$ & $21,16 \pm 5,01$ & $Y=23,94 \pm 6,12$ \\
\hline $\begin{array}{l}\text { Shear, } \mathrm{kgf} / \mathrm{cm}^{31} \\
\text { Shear, } \mathrm{kgf} / \mathrm{cm}^{3}\end{array}$ & $3,61 \pm 0,92$ & $3,79 \pm 0,77$ & $3,95 \pm 1,01$ & $Y=3,78 \pm 1,25$ \\
\hline $\begin{array}{l}\text { Painel, pontos }{ }^{2} \\
\text { Panel, points }\end{array}$ & $7,17 \pm 0,41$ & $6,66 \pm 0,51$ & $6,50 \pm 0,84$ & $Y=6,77 \pm 0,65$ \\
\hline $\begin{array}{l}\text { Palat, pontos }{ }^{3} \\
\text { Palat, points }\end{array}$ & $6,50 \pm 1,21$ & $6,83 \pm 0,75$ & $7,00 \pm 0,60$ & $Y=6,77 \pm 0,86$ \\
\hline $\begin{array}{l}\text { Sucul, pontos } \\
\text { Juice, poits }\end{array}$ & $6,72 \pm 0,64$ & $6,67 \pm 0,21$ & $7,27 \pm 1,00$ & $\mathrm{Y}=6,88 \pm 0,71$ \\
\hline
\end{tabular}

1 Maiores valores indicam menor maciez.

1 Higher values correspond to tougher meat.

29 - extremamente macia; 8 - muito macia; 7 - macia; 6 - levemente acima da média; 5 - média.

29 - extremely tender; 8-very tender; 7 - tender; 6 - slightly above average; 5 - average.

39 - extremamente saborosa; 8 - muito saborosa; 7 - saborosa; 6 - levemente acima da média; 5 - média.

39 - extremely flavorful; 8- very flavorful; 7 - flavorful; 6 - slightly above average; 5 - average.

49 - extremamente suculenta; 8 - muito suculenta; 7 - suculenta; 6 - levemente acima da média; 5 - média.

49 - extremely juicy; 8 - very juicy; 7 - juicy; 6 - slightly above average; 5 - average. 
associado com o aumento no período de terminação e, conseqüentemente, com a idade do animal, interferindo negativamente na maciez da carne. Efeito do tempo de terminação na maciez da carne foi constatado por Moody et al. (1970) e Van Koevering et al. (1995), os quais averiguaram que em animais alimentados por períodos longos a maciez decresceu.

A maciez média dos três pesos de abate foi de 6,77 pontos, superior ao relatado para animais desta categoria de idade (Restle et al., 1999). Segundo Boleman et al. (1996), a alimentação de animais no período de terminação com dieta de elevada densidade energética favorece as características sensoriais da carne, inclusive a maciez, em função da rápida síntese de proteínas, aumentando a proporção de colágeno solúvel na carne, o que provavelmente ocorreu no presente experimento dado ao elevado ganho de peso (Arboitte et al., 2004).

Quanto à palatabilidade da carne, não houve influência do peso de abate. Na média, a pontuação obtida foi de 6,77 pontos, classificando-se como carne entre "acima da média e palatável”. Embora sem diferença significativa, houve correlação positiva entre a palatabilidade com a espessura de gordura de cobertura ( $r=0,37 ; \mathrm{P}=0,12)$, com o marmoreio $(r=0,27$; $\mathrm{P}=0,26)$ e significativamente com o teor de extrato etéreo $(\mathrm{r}=0,51 ; \mathrm{P}=0,03)$, o que está de acordo com resultados de Preston \& Willis (1970), Restle et al. (1996) e Costa et al. (2002) de que carcaças com maior grau de acabamento, marmoreio e teor de lipídios apresentam carne de melhor palatabilidade, indicando que a gordura presente no interior das células musculares possuem substâncias flavorizantes agradáveis ao paladar.

A suculência da carne comportou-se de maneira similar com o aumento do peso de abate. A suculência da carne nos diferentes pesos de abate foi classificada entre "acima da média e suculenta" (6,88 pontos). Houve relação inversa entre a quebra no processo de cocção e a suculência da carne, comprovado pelo coeficiente de correlação de $-0,18(\mathrm{P}=0,46)$. As características sensoriais da carne correlacionaram-se positivamente entre si, de 0,33 entre palatabilidade e suculência e de 0,22 entre esta última e a maciez. Isto indica que uma carne macia também é suculenta e palatável, concordando com os resultados de Field et al. (1966), Wheeler et al. (1996), Costa et al. (2002) e Vaz et al. (2002).

Na Tabela 5, são apresentados os valores de extrato etéreo e de colesterol no músculo Longissimus dorsi, de acordo com o peso de abate.

O conteúdo médio de extrato etéreo, que representa os lipídios depositados intra e intercelulares, não variaram frente ao aumento no peso de abate, sendo na média de 1,63\%, com tendência a aumentar, passando de 0,96 para $1,75 \%$ do menor para o maior peso de abate. Valor médio superior (2,35\%) foi relatado por Costa et al. (2002), ao abaterem novilhos Red Angus superprecoces com 340, 370, 400 e 430 kg. A porcentagem de extrato etéreo correlacionou-se positivamente com a espessura de gordura subcutânea $(\mathrm{r}=0,42 ; \mathrm{P}=0,08)$ e o marmoreio da carne $(\mathrm{r}=0,46$; $\mathrm{P}=0,05$ ), porém com o percentual de gordura não foi verificada correlação significativa.

Quanto ao teor de colesterol, também foi verificada similaridade entre os pesos de abate estudados, que na média foi de 53,12 mg/100 g de músculo Longissimus dorsi. Nota-se, porém, que houve tendência de incremento linear.

Em estudo que avaliou diferentes pesos de abate em novilhos Red Angus nas características da carcaça e da carne, Costa et al. (2002) reportaram similaridade com o aumento do peso de abate no conteúdo de colesterol da carne (43,07 mg/100 g), concordando

Tabela 5 - Conteúdo de extrato etéreo e colesterol no músculo Longissimus dorsi, de acordo com o peso de abate

Table 5 - Means for ether extract and cholesterol content in Longissimus dorsi muscle, according to the slaughter weight

\begin{tabular}{|c|c|c|c|c|}
\hline \multirow[t]{2}{*}{$\begin{array}{l}\text { Variáveis } \\
\text { Variable }\end{array}$} & \multicolumn{3}{|c|}{$\begin{array}{l}\text { Peso de abate } \\
\text { Slaughter weight }\end{array}$} & \multirow{2}{*}{$\begin{array}{l}\text { Médias } \\
\text { Means }\end{array}$} \\
\hline & P425 & P 467 & P510 & \\
\hline $\begin{array}{l}\text { Extrato etéreo, \% } \\
\text { Ether extract, \% }\end{array}$ & $0,96 \pm 0,88$ & $2,20 \pm 1,01$ & $1,75 \pm 1,14$ & $Y=1,63 \pm 1,09$ \\
\hline $\begin{array}{l}\text { Colesterol, } \mathrm{mg} / 100 \mathrm{~g} \\
\text { Cholesterol, } \mathrm{mg} / 100 \mathrm{~g}\end{array}$ & $48,23 \pm 13,89$ & $54,67 \pm 9,74$ & $56,46 \pm 5,35$ & $Y=53,12 \pm 10,31$ \\
\hline
\end{tabular}

R. Bras. Zootec., v.33, n.4, p.959-968, 2004 
com os resultados do presente estudo. Os resultados de Stromer et al. (1966) reportaram que os grupos de animais mais jovens (de 15-18 meses e de 20-24 meses de idade) apresentaram menor conteúdo de colesterol na gordura intramuscular que os animais do grupo de maior maturidade (6 ou mais anos de idade). Ainda segundo os autores, o colesterol encontra-se em diferentes proporções nos tecidos que compõem a carcaça, onde os lipídios intramusculares apresentam mais colesterol que a gordura subcutânea, sugerindo que este é, em maior parte, originário das membranas celulares e estruturas intracelulares.

Correlação significativa foi verificada entre o teor de extrato etéreo e o de colesterol da carne $(\mathrm{r}=0,60$; $\mathrm{P}=0,01)$. Segundo Stromer et al. (1966) e Costa et al. (2002), esta elevada associação ocorre em função dos teores de extrato etéreo incluir a gordura localizada inter e intracelularmente, sendo esta última a que contém os maiores níveis de colesterol.

Ao avaliarem a concentração de colesterol do músculo Longissimus dorsi in natura ou cozido e da gordura subcutânea de bovinos alimentados por 0,77 , 128 e 182 dias, das raças Chianina ou cruzas de Hereford x Aberdeen Angus, Wheeller et al. (1987) não constataram diferença significativa. O músculo Longissimus dorsi in natura apresentou colesterol de 63,32 mg/100 g de músculo e o cozido, de $80,27 \mathrm{mg} /$ 100 g de músculo (diferença de 26,85\%). O aumento na concentração do colesterol na amostra de músculo cozido decorreu da perda de umidade.

Xie et al. (1996), utilizando novilhos alimentados por 90 e 170 dias, constataram que o conteúdo de colesterol (mg/100 g de músculo) da gordura intramuscular e da subcutânea aumentou ao elevarem o tempo de alimentação, comprovando que o nível de colesterol aumentou em decorrência do incremento no total de ácidos graxos responsáveis pelo HDL. Terrel et al. (1969), estudando a influência do peso de abate de novilhos e novilhas Aberdeen Angus, constataram que o conteúdo de colesterol foi maior nos animais abatidos com $455 \mathrm{~kg}(82,40 \mathrm{mg} / 100 \mathrm{~g}$ de músculo) em relação aos abatidos com 368 e 420 kg (77,83 e 72,15 mg/100 g de músculo, respectivamente).

Van Koevering et al. (1995) constataram, em novilhos superprecoce mestiços de raça britânica com raça continental, alimentados por 105, 119, 133 e 147 dias, que a concentração de colesterol (mg/100 g de músculo) no Longissimus dorsi aumentou com o tempo de alimentação. A carne de novilhos alimentados por 119 dias ou menos teve menor concentração de colesterol que de novilhos alimentados por 133 dias ou mais. O teor de lipídios presente no Longissimus dorsi aumentou com o tempo de alimentação, onde novilhos alimentados por 105 dias tiveram menos lipídios concentrados no músculo que os outros grupos de abate. Estes resultados concordam com os de Moody et al. (1970), em que a concentração do extrato etéreo do músculo Longissimus dorsi foi maior para novilhos alimentados por 56 dias ou mais em relação aos alimentados por 28 dias.

\section{Conclusões}

Recomenda-se que os novilhos sejam abatidos com $425 \mathrm{~kg}$, tendo em vista que as carcaças apresentaram espessura de gordura adequada, maior proporção de músculo e carne com características organolépticas similares à dos animais abatidos com pesos mais elevados.

Não houve alteração no conteúdo de colesterol da carne, embora o grau de marmoreio tenha aumentado com o incremento do peso dos animais.

\section{Literatura Citada}

ARBOITTE, M.Z.; RESTLE, J; ALVES FILHO, D.C. et al. Desempenho em confinamento e características da carcaça e da carne de novilhos 5/8 Nelore 3/8 Charolês abatidos em três estádios de desenvolvimento. Revista Brasileira de Zootecnia, v.33, n.4, p.947-958, 2004.

BERG, R.T.; BUTTERFIELD, R.M. New concepts of cattle growth. 5.ed. New York: 1976. 240p.

BOGGS, D.L.; MERKEL, R.A. Live animal, carcass evaluation and selection manual. Dubuque: Kendall/Hunt Publishing Company, 1979. 199p.

BOLEMAN, S.J.; MILLER, R.K.; BUYCK, M.J. Influence of realimentation of mature cows on maturity, color, collagen solubility, and sensory characteristics. Journal of Animal Science, v.74, p.2187-2194, 1996.

COSTA, E.C.; RESTLE, J.; VAZ, F.N. et al. Características da carcaça de novilhos Red Angus superprecoces abatidos com diferentes pesos. Revista Brasileira de Zootecnia, v.31, p.417-428, 2002 (suplemento).

DEL DUCA, L.O.A.; MORAES, C.A.C.; SALOMONI, E. et al. Efeito do peso de abate nas características quantitativas da carcaça de novilhos Ibagé. In: REUNIÃO ANUAL DA SOCIEDADE BRASILEIRA DE ZOOTECNIA, 36., 1999, Porto Alegre. Anais...Viçosa, MG: Sociedade Brasileira de Zootecnia, 1999. p.357.

FIELD, R.A.; NELMS, G.E.; SCHOONOVER, C.O. Effects of age, marbling and sex on palatability of beef. Journal of Animal Science, v.25, p.360-366, 1966.

FOLCH, J.; LEES, M.; STAMLEY, G.H.S. A simple method for the isolation and purification of total lipids from animal tissue. Journal Biological Chemical, v.226, p.497-509, 1957. 
GALVÃO, J.G.; FONTES, C.A.A.; PIRES, C.C. et al. Características e composição da carcaça de bovinos não-castrados, abatidos em três estágios de maturidade (estudo II) de três grupos raciais. Revista da Sociedade Brasileira de Zootecnia, v.20, p.502-512, 1991.

HANKINS ,O.G.; HOWE, P.E. Estimation of the composition of beef carcas and cuts. Washington: Unite Stade Departament of Agriculture, 1946. (Technical Bulletin, 926).

JORGE, A.M.; FONTES, C.A.A.; PAULINO, M.F. et al. Desempenho produtivo de animais de quatro Raças Zebuínas, abatidos em três estádios de maturidade. 2 Características da carcaça. Revista Brasileira de Zootecnia, v.28, p.381-387, 1999.

LAWRIE, R. Developments in meat science. London: Elsevier Applied Science, 1981. 342p.

MAY, S.G.; DOLEZAL, H.G.; GILL, D.R. et al. Effects of days fed, carcass grade traits, and subcutaneous fat removal on postmortem muscle characteristics and beef palatability. Journal of Animal Science, v.70, p.444-453, 1992.

MOODY, W.G.; LITTLE Jr., J.E.; THRIFT, F.A. et al. Influence of length of feeding a high roughage ratio on quantitative and qualitative characteristics of beef. Journal of Animal Science, v.31, p.866-873, 1970.

MÜLLER, L. Normas para avaliação de carcaças e concurso de carcaça de novilhos. 2.ed. Santa Maria: Universidade Federal de Santa Maria, 1987. 31p.

MÜLLER, L.; MAXON, W.E.; PALMER, A.Z. et al. Evaluación de técnicas para determinar la composición de la canal. In: Associação Latina de Produção Animal. 1973. GuadalajaraMéxico. Anais... Guadalajara: [sn]. 1973.

NATIONAL RESEARCH COUNCIL - NRC. Nutrient requirements of domestic animals. 7.rev.ed. Washington, D.C.: National Academy Press, 1996. 242p.

PRESTON, T.R.; WILLIS, M.B. Intensive beef production. Oxford: Pergamon Press, 1970. 544p.

RESTLE, J.; BRONDANI, I.L.; PASCOAL, L.L. et al. Produção intensiva com qualidade em bovinos de corte. Santa Maria: Universidade Federal de Santa Maria, 1998. 125p.

RESTLE, J.; KEPLIN, L.A.S.; VAZ, F.N. et al. Qualidade da carne de novilhos Charolês confinados e abatidos com diferentes pesos. Ciência Rural, v.26, n.3, p.463-466, 1996.

RESTLE, J.; KEPLIN, L.A.S.; VAZ, F.N. Características quantitativas da carcaça de novilhos Charolês, abatidos com diferentes pesos. Pesquisa Agropecuária Brasileira, v.32, n.8, p.851-856, 1997.

RESTLE, J.; VAZ, F.N.; QUADROS, A.R.B. et al. Características de carcaça e da carne de novilhos de diferentes genótipos Hereford x Nelore. Revista Brasileira de Zootecnia, v.28, p.1245-1251, 1999.

RESTLE, J.; CERDOTES, L.; VAZ, F.N. et al. Características de carcaça e da carne de novilhas Charolês e $3 / 4$ Charolês $1 / 4$ Nelore, terminadas em confinamento. Revista Brasileira de Zootecnia, v.30, p.1065-1075, 2001, suplemento 3.

STATISTICAL ANALYSES SYSTEM - SAS. SAS/STAT. User's guide: statistics. 4.ed. Cary: 1997. 943p.

SCHNELL, T.D.; BELK, K.E.; TATUM, J.D. Performance, carcass, and palatability traits of cull cows fed high-energy diets for $0,14,28,42$, or 56 days. Journal of Animal Science, v.75, p.1195-1202, 1997.

STROMER, M.H.; GOLL, D.E.; ROBERTS, J.H. Cholesterol in subcutaneous and intramuscular lipid depots from bovine carcasses of different maturity and fatness. Journal of Animal Science, v.25, p.1145-1152, 1966.
TERREL, R.N.; SUESS, G.G.; BRAY, R.W. Influence of Sex, liveweight and anatomical location on bovine lipids. II. Lipids components and subjetive scores of six muscle. Journal of Animal Science, v.28, p.454-458, 1969.

TOWSEND, M.R. Desempenho em confinamento de diferentes categorias animais e características de carcaça e da carne de novilhos e vacas. Santa Maria: Universidade Federal de Santa Maria, 1991. 191p. Dissertação (Mestrado em Zootecnia) - Universidade Federal de Santa Maria, 1991.

VALLE, E.R. Mitos e realidades sobre o consumo de carne bovina. <http://www.cnpgc.embrapa.br/publicacoes/doc/ doc100/005comparacaocarnes.html>. Acesso em: 03 de janeiro de 2003.

Van KOEVERING, M.T.; GILL, D.R.; OWENS, F.N. et al. Effect of time on feed on performance of feedlot steers, carcass characteristics, and tenderness and composition of longissimus muscle. Journal of Animal Science, v.73, p.21-28, 1995.

VAZ, F.N.; RESTLE, J. Aspectos quantitativos da carcaça e da carne de machos Hereford inteiros ou castrados, abatidos aos quatorze meses. Revista Brasileira de Zootecnia, v.29, p.1894-1901, 2000.

VAZ, F.N.; RESTLE, J.; CERDOTES, L. et al. Características qualitativas das carcaças e da carne de novilhos ou novilhas Braford superprecoces, terminados com suplementação em pastagem cultivada com pastejo controlado. In: REUNIÃO ANUAL DA SOCIEDADE BRASILEIRA DE ZOOTECNIA, 38., 2001, Piracicaba. Anais... Piracicaba: Fundação de Estudos Agrários “Luiz de Queiroz”, 2001. p.1532-1534.

VAZ, F.N.; RESTLE, J.; QUADROS, A.R.B. et al. Características da carcaça e da carne de novilhos e de vacas de descarte Hereford, terminados em confinamento. Revista Brasileira de Zootecnia, v.31, p.1501-1510, 2002 (suplemento).

WHEELER, T.L.; DAVIS, G.W.; STOECKER, B.J. et al. Cholesterol concentration of longissimus muscle, subcutaneous fat and serum of two beef cattle breed types. Journal of Animal Science, v.65, p.1531-1537, 1987.

WHEELER, T.L.; CUNDIFF, L.V.; KOCH, R.M. et al. Characterization of biological types of cattle (Cycle IV): carcassa traits and longissimus palatability. Journal of Animal Science, v.74, p.1023-1035, 1996.

WILLIAMS, S.E.; TATUM, J.D.; STATON, T.L. The effects of muscle thickness and time on feed on hot fat trim yields, carcass characteristics and boneless subprimal yields. Journal of Animal Science, v.67, p.2669-2676, 1989.

XIE,Y.R.; BUSBOOM, J.R.; CORNFORTH, D.P. et al. Effects of time on feed and post-mortem aging on palatability and lipid composition of crossbred Wagyu beef. Meat Science, v.43, n.2, p.157-166, 1996.

Recebido em: 13/03/03 Aceito em: 25/08/03 